\title{
STATISTICAL ANALYSIS OF MEGALITHIC TOMB ORIENTATIONS IN THE IBERIAN PENINSULA AND NEIGHBOURING REGIONS
}

\author{
A. CÉSAR GONZÁLEZ GARCIA, Universidad Autónoma de Madrid, and \\ JUAN ANTONIO BELMONTE, Instituto de Astrofísica de Canarias
}

After nearly two decades of intense research, we now know that most groups of Western European megalithic tombs reveal patterns of orientations showing similarities amongst themselves. In other words, the orientation is coherent within different groups of megaliths. In most cases the pattern of orientation appears to relate to the sectors of the horizon where the sun and moon rise, pass across the sky, or set. ${ }^{1}$

Various models and schemes have been proposed to explain the orientation diagrams for certain groups. In particular, the pattern of orientation of the 'antas' in central Alentejo (Portugal) has attracted considerable interest. It was soon realized that most of these seven-stone dolmens were consistent with the position of sunrise (presumably) in the autumn months. ${ }^{2}$ However the histogram, or the kernel density distribution, shows a large concentration of orientations towards points in the horizon slightly off to the south of east, and Da Silva has proposed that the pattern of orientation is consistent with the full moon's rising immediately following the spring equinox. ${ }^{3}$ However, it is worth noting that in many other cases, Hoskin has proposed a sunrise/sun climbing custom to explain similar orientation patterns. ${ }^{4}$

The Alentejo dolmens constitute a paradigmatic case, since either the sun or the moon, at different times of the year, could explain the orientation pattern. In this sense, it would seem extremely difficult to go one step forward and distinguish between the two possibilities in any objective way. But, if we want archaeoastronomy to present data and conclusions of use in understanding peoples of the past, we do need to go one step ahead. However, subjectivity in the decision-making process is indeed hampering any advance in this process. A possible way of overcoming this problem is through systematic statistical analysis and comparison of data with suitable models in order to find those that better reproduce/explain the given data.

Statistics and modelling have been used in the past both to shed light on the orientations of some groups of megalithic monuments and to test their significance. ${ }^{5}$ In some cases the results have provided backing for a given hypothesis. Thus, Patrick and Freeman performed a cluster analysis on Ruggles's data to verify some of his hypotheses regarding the orientation of Scottish megaliths. ${ }^{6}$ Also, as mentioned above, da Silva compared models for the rising of the spring full moon with the antas in central Alentejo. Our research group carried out a comprehensive study on the orientation patterns of the megalithic tombs in southern France, Sardinia and Tunisia, comparing these patterns with models for the first or last sighting of the crescent or last-crescent (waning) moon, in an attempt to falsify the sunrising / sun climbing customs for these particular groups of monuments. ${ }^{7}$ 
The statistical tests provide evidence as to the degree of confidence we can have that a particular astronomical event was the intended target. Broader indicators of the cultural context, and their interpretation (e.g. in the framework of cognitive anthropology $\mathrm{y}^{8}$ ) are needed in order to provide theories about the motivation for such targets. Statistical tests provide the tools to perform a more fundamental step, by distinguishing between different possible targets.

In the present paper we aim to make this comparison by applying a specific tool of cluster analysis called the dendrogram. This kind of diagram is extensively used in other fields of the natural and social sciences. In particular, their applicability for genetic studies and linguistics is well known. ${ }^{9}$

One step further will be to compare the clusters with several different astronomical models. We shall carry out a preliminary classification by using a technique to group the clusters around some of these models. This technique will allow us to discern which clusters tend to prefer a given model, which could later be confirmed by proper group-by-group modelling. We will achieve such classification through a technique known as principal components analysis.

\section{The Sample}

Our sample is defined by several groups (29 in number) of monuments located in, or very close to, the Iberian Peninsula, plus six groups outside this area: two in southern France (Languedoc and Provence) and two in the Islands (Corsica and Sardinia), as described in Hoskin's Tombs, temples; one in Brittany (allées couvertes) $;{ }^{10}$ and a set of dolmens in the Golan Heights. This amounts to nearly 1500 megalithic tombs in total. We have divided these megaliths into a total of 35 groups, mainly following Tombs, temples grouping, although some have been grouped together following a larger provincial or regional division, i.e. the groups are identified on grounds of location. We have complemented Hoskin's data for the central parts of Spain with data provided by Gil-Merino and collaborators for the province of Burgos ${ }^{11}$ and our own measurements in other areas of central Spain (see Table 1 and Figure 1).

The data for the megalithic tombs of the Golan Heights are provided in Table 2 (see also Figure 1). We have measured 45 dolmens close to the ruins of Gamla. These dolmens are rather small, they appear to be clustered in three groups, and tend to be opened facing the western horizon. Given the tiny size of these dolmens, the intended orientation could be considered to be as accurate as $1^{\circ}$. Mount Tabor is an important landmark in the west direction although, except for a few dolmens, there is no clear connection between the direction of this mountain and the direction faced by the tombs. Figure 2 gives the orientation diagrams for the dolmens both in central Spain (left) and in the Golan Heights (right). Figure 3 presents the histogram for the declination of the dolmens of Gamla. 
TABLE 1. Dolmens in the central area of Spain. Eight new dolmens have been measured so far, four in the province of Zamora (ZA), two in Toledo (TO), and one each in Valladolid (VA) and Avila (AV). For each dolmen is shown the azimuth, the angular height, the latitude, and the corresponding declination. Two dolmens, in Soria (SO) and Guadalajara (GU), are published in Tombs, temples but have been revisited and are included here to complete the sample of this area.

$\begin{array}{lcccc}\text { Dolmen } & \mathrm{a}\left({ }^{\circ}\right) & \mathrm{h}\left(^{\circ}\right) & \text { Lat. }\left(\left(^{\circ}\right)\right. & \delta\left(^{\circ}\right) \\ \text { Granucillo (ZA) } & 101^{\frac{3}{4}} & 0 \frac{1}{4} & 42^{\circ} 03^{\prime} & -8^{\frac{1}{2}} \\ \text { S. Adrián (ZA) } & 103 \frac{1}{4} & -0 \frac{1}{4} & 42^{\circ} 03^{\prime} & -10 \\ \text { Arrabalde (ZA) } & 116 & 0 & 42^{\circ} 06^{\prime} & -19 \\ \text { El Tesoro (ZA) } & 111^{\frac{3}{4}} & 0 \frac{1}{2} & 42^{\circ} 04^{\prime} & -15 \frac{1}{2} \\ \text { Zumacales (VA) } & 123 \frac{1}{4} & -1 & 41^{\circ} 35^{\prime} & -24^{\frac{3}{4}} \\ \text { Brenuy (AV) } & 116 & 2 & 40^{\circ} 40^{\prime} & -18 \\ \text { Carrascosa (SO) } & 133 & 1 & 41^{\circ} 55^{\prime} & -29^{\frac{3}{4}} \\ \text { Azután (TO) } & 97 \frac{1}{4} & 0 & 39^{\circ} 47^{\prime} & -5 \frac{1}{2} \\ \text { Melque (TO) } & 152^{\frac{1}{2}} & 2 & 39^{\circ} 43^{\prime} & -41_{4}^{\frac{1}{4}} \\ \text { Aguilar (GU) } & 114 & 0 \frac{3}{4} & 41^{\circ} 03^{\prime} & -17 \frac{1}{2}\end{array}$

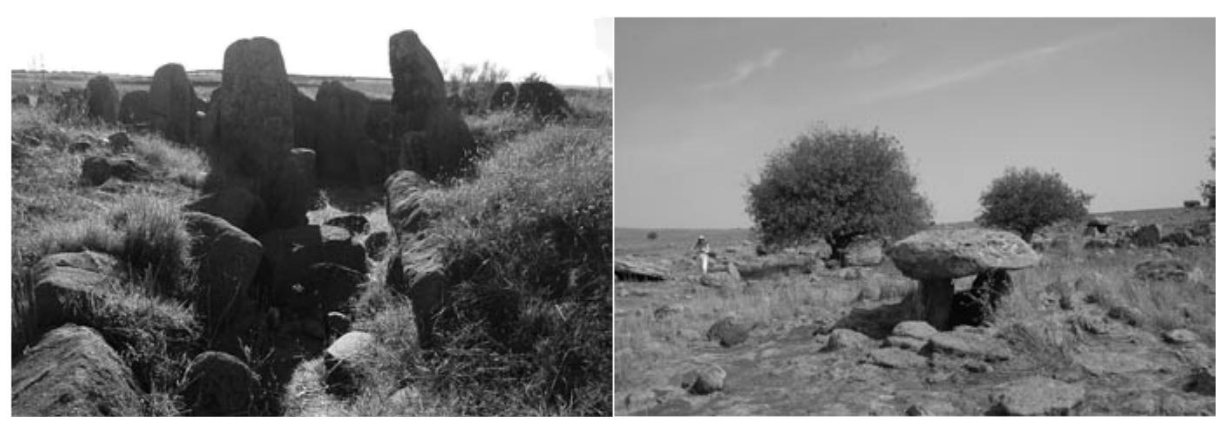

FIG. 1. The isolated dolmen of Azután (left), in the Spanish province of Toledo, has stones as high as $2.5 \mathrm{~m}$ and a corridor of $8 \mathrm{~m}$. In contrast, the dolmens of Gamla, in the Golan Heights are tiny monuments (see the human figure for reference) for no more than a single burial but concentrated in large groups. Photographs by A. César González García and Juan A. Belmonte, respectively.

\section{Data Mining}

We use raw data, i.e. the measured azimuths for each of the megaliths. The reason for this is to avoid any explicit reference to latitude or longitude in the parameters characterizing the group, so that any possible relation that may exist between different groups we could safely recognize as being linked to the orientation patterns. Of course, when these data are later compared to the control model sample of astronomical targets, the latitude and horizon altitude are implicitly used. We then adopt the latitude corresponding to the centre of the Peninsula. The error introduced by this procedure is set out in the calculations shown below and it appears to be quite small. The use of azimuths is further justified because in our sample we have both east- and west-oriented monuments and thus we have monuments facing rising and setting astronomical 'targets', which would be more difficult to model with 
TABLE 2. Orientations of dolmens in Gamla, in the Golan Heights. For each measured monument is shown the azimuth, the angular height and the corresponding declination. The common latitude is $32^{\circ} 54^{\prime}$.

$\begin{array}{ccccccccc}\mathrm{a}\left({ }^{\circ}\right) & \mathrm{h}\left({ }^{\circ}\right) & \delta\left(^{\circ}\right) & \mathrm{a}\left({ }^{\circ}\right) & \mathrm{h}\left({ }^{\circ}\right) & \delta\left(^{\circ}\right) & \mathrm{a}\left({ }^{\circ}\right) & \mathrm{h}\left({ }^{\circ}\right) & \delta\left(^{\circ}\right) \\ 213 & 0 & -44 \frac{3}{4} & 259 & 0 & -9 \frac{1}{4} & 270 & 0 & 0 \\ 213 & 0 & -44 \frac{3}{4} & 262 & 0 & -6 \frac{3}{4} & 270 & 0 & 0 \\ 232 & 1 & -30 \frac{1}{2} & 262 & 0 & -6 \frac{3}{4} & 270 & 0 & 0 \\ 235 & 1 & -28 \frac{1}{4} & 263 & 0 & -6 & 271 & 0 & 0 \frac{3}{4} \\ 242 & 0 & -23 \frac{1}{4} & 266 & 0 & -3 \frac{1}{2} & 271 & 0 & 0 \frac{3}{4} \\ 244 & 0 & -21 \frac{1}{2} & 266 & 0 & -3 \frac{1}{2} & 271 & 0 & 0 \\ 248 & 0 & -18 \frac{1}{4} & 266 & 0 & -3 \frac{1}{2} & 274 & 0 & 3 \frac{1}{2} \\ 249 & 0 & -17 \frac{1}{2} & 267 & 0 & -2 \frac{1}{2} & 274 & 0 & 3 \frac{1}{2} \\ 249 & 0 & -17 \frac{1}{2} & 267 & 0 & -2 \frac{1}{2} & 274 & 0 & 3 \frac{1}{2} \\ 252 & 0 & -15 & 268 & 0 & -1 \frac{3}{4} & 274 & 0 & 3 \frac{1}{2} \\ 258 & 0 & -10 & 268 & 0 & -1 \frac{3}{4} & 275 & 0 & 4 \frac{1}{4} \\ 258 & 0 & -10 & 268 & 0 & -1 \frac{3}{4} & 275 & 0 & 4 \frac{1}{4} \\ 259 & 0 & -9 \frac{1}{4} & 269 & 0 & -0 \frac{3}{4} & 276 & 1 & 5 \frac{1}{2} \\ 259 & 0 & -9 \frac{1}{4} & 269 & 0 & -0 \frac{3}{4} & 276 & 1 & 5 \frac{1}{2} \\ 259 & 0 & -9 \frac{1}{4} & 269 & 0 & -00_{4}^{\frac{3}{4}} & 279 & 1 & 8\end{array}$

declination data only.

Finally, it must be noted that when employing the orientation data in this way, we use a linear axis to represent a circular quantity and a possible problem would be the wrap-around of the data facing north. However, few tombs from our sample face these orientations and we profit from this in the present case. In the case where we had a significant number of orientations facing north, we could easily introduce the wrap-around in the algorithms to take this into account.

Also, by using all these megaliths, we include monuments of different typologies and epochs. This coarse procedure is twofold: on the one hand, we have the possibility to perform reliable statistical studies and, on the other, we could test for any
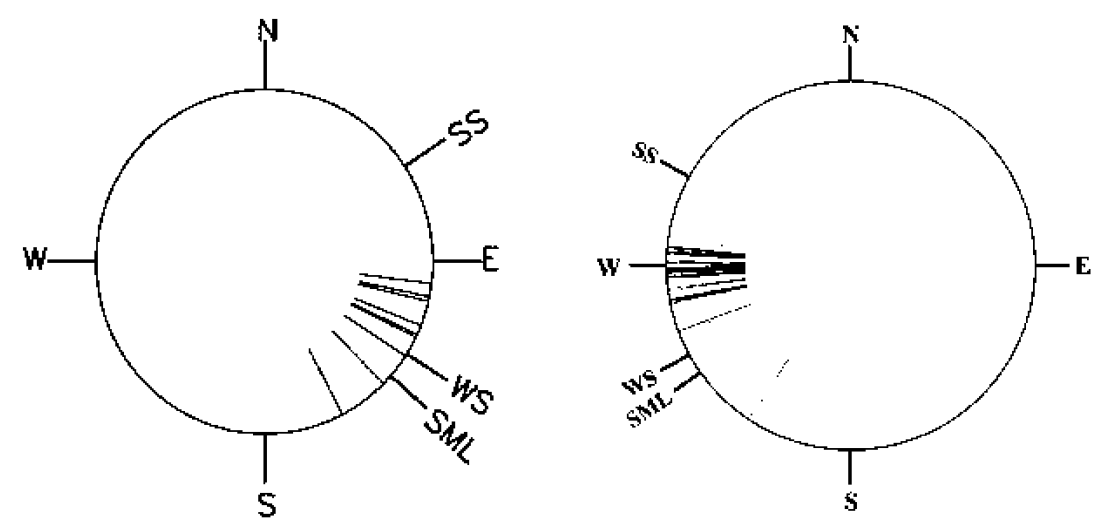

FIG. 2. Orientation diagrams for the passage graves in central Spain (left), as presented in Table 1, and for the dolmens in the Golan (right), as presented in Table 2. 


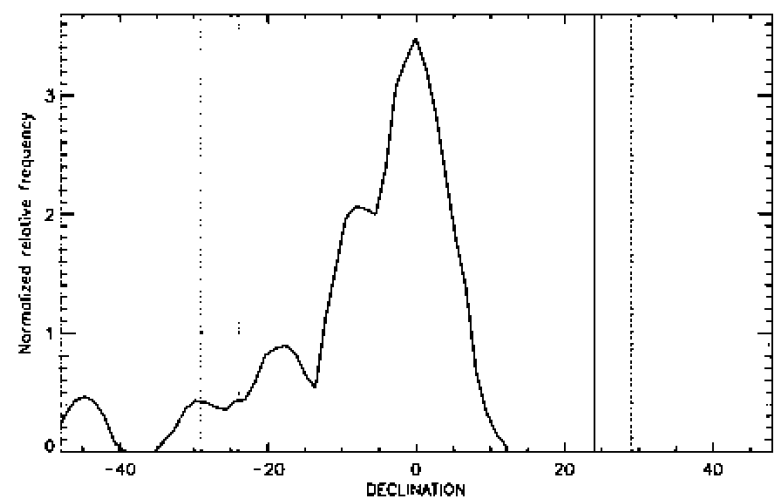

FIG. 3. Declination histogram for the dolmens in the Golan Heights. Note the high concentration of monuments with an orientation close to due west.

possible persistence of orientating traditions if existent.

To characterize the different groups of study we must define parameters that characterize the various groups. We have investigated several possibilities and have finally come to the conclusion that the kernel density distributions of each group are well represented by the following seven numbers (see Table 3 ): $:^{12}$ the mean azimuth, the median azimuth, the standard deviation of the azimuthal distribution, the maximum azimuth of the distribution, the minimum azimuth of the distribution, and the azimuth of the first and second (if existent) maximum in the azimuth kernel density diagrams of the group. In case the second maximum is non-existent this is taken to be equal to the first. The median, maximum and minimum azimuths provide measurements of the range of azimuths covered by a population. The mean and the standard deviation are the first two statistical moments for a population and provide information on the most probable values within which the majority of the data are to be found. Finally, the two maxima of the kernel density distribution give the azimuths where we may find the largest concentration of azimuths in that population of megaliths. We shall call these numbers our "genetic markers".

In the following, we use two statistical tools, the Cluster Analysis and a visualization of such called the dendrogram, and the Principal Components Analysis. The first identifies groupings on the grounds of their distance on a given $n$-dimensional parameter space. The second transforms the variables defined above, which might not be independent variables, into a set of independent parameters. At the same time, a few of these variables may explain most of the variation on the data pool, allowing reduction in the number of parameters.

\section{Cluster Analysis and Dendrogram Diagram}

We have used cluster analysis ${ }^{13}$ to identify, among our data, those groups that may be grouped together according to their orientation patterns. Cluster analysis uses a set 
TABLE 3. Input data for the cluster analysis and for the principal components analysis. The table presents the cluster name, the acronym, the number of members and the corresponding statistical data for every group. Note that the complete analysis includes a total of nearly 1500 megalithic monuments. See the text for further details.

\begin{tabular}{|c|c|c|c|c|c|c|c|c|c|}
\hline Cluster & Acronym & \# & $\overline{\mathrm{a}}$ & $\operatorname{med}(a)$ & $\sigma(\mathrm{a})$ & $\operatorname{Max}(a)$ & $\operatorname{Min}(\mathrm{a})$ & $a_{\max 1}$ & $\mathrm{a}_{\max 2}$ \\
\hline Alentejo & ALEN & 173 & 98.4 & 100 & 12.1 & 129 & 61 & 103.1 & 92 \\
\hline Almería & ALME & 99 & 113.6 & 111 & 25.1 & 216 & 62 & 113.6 & 96 \\
\hline Badajoz & BADA & 10 & 62.0 & 65 & 21.7 & 92 & 26 & 67.2 & 90 \\
\hline Baleares & BALE & 9 & 248.9 & 245 & 19.1 & 278 & 220 & 244.9 & 262 \\
\hline Barcelona & BRNA & 10 & 154.8 & 140 & 54.9 & 270 & 91 & 120.8 & 221 \\
\hline Cáceres & CACE & 34 & 101.2 & 99 & 12.3 & 143 & 76 & 97.9 & 107 \\
\hline Cádiz & CADZ & 5 & 185.4 & 216 & 86.2 & 234 & 32 & 220.3 & 30 \\
\hline Central & CENT & 10 & 117.2 & 116 & 16.6 & 152.5 & 97.3 & 118.2 & 100 \\
\hline Cerdaña & CERD & 22 & 117.6 & 121 & 24.8 & 161 & 73 & 121.5 & 85 \\
\hline Córdoba & CORD & 14 & 83.2 & 87 & 15.1 & 106 & 61 & 89.1 & 62 \\
\hline Douro N & DOUR & 11 & 86.5 & 93 & 26.5 & 107 & 10 & 95.7 & 100 \\
\hline Elvas & ALENE & 20 & 98.8 & 101 & 17.5 & 129 & 71 & 100.0 & 75 \\
\hline Galicia & GALI & 33 & 109.2 & 107 & 16.6 & 137 & 65 & 102.3 & 126 \\
\hline Gerona & GRNA & 22 & 144.0 & 148 & 48.5 & 244 & 55 & 140.4 & 185 \\
\hline Granada & GRDA & 143 & 121.7 & 122 & 34.7 & 204 & 20 & 120.0 & 140 \\
\hline Guipúzcoa & GUIP & 26 & 100.5 & 97 & 19.5 & 157 & 77 & 98.5 & 83 \\
\hline Huelva & HLVA & 33 & 99.8 & 92 & 28.2 & 179 & 52 & 88.1 & 120 \\
\hline Lisboa & LISB & 9 & 127.4 & 111 & 40.7 & 213 & 80 & 106.2 & 155 \\
\hline Málaga & MLGA & 12 & 98.5 & 96 & 35.0 & 180 & 45 & 77.3 & 130 \\
\hline Minho & MNHO & 12 & 99.2 & 101 & 10.8 & 116 & 80 & 102.0 & 90 \\
\hline Miranda & MRND & 7 & 117.9 & 119 & 11.1 & 130 & 101 & 125.1 & 105 \\
\hline Mondego & MDGO & 43 & 103.5 & 106 & 20.7 & 138 & 44 & 116.9 & 90 \\
\hline Norte & NORT & 23 & 138.5 & 128 & 31.1 & 228 & 94 & 122.6 & 142 \\
\hline Pirineos & PIRI & 100 & 175.6 & 168 & 47.2 & 304 & 48 & 165.3 & 150 \\
\hline Portugal N & PNOR & 8 & 119.3 & 128 & 36.1 & 174 & 73 & 123.5 & 80 \\
\hline Portugal S & PSUR & 24 & 100.6 & 108 & 19.4 & 127 & 54 & 108.2 & 80 \\
\hline Salamanca & SLMC & 21 & 111.0 & 112 & 12.2 & 133 & 84 & 112.9 & 87 \\
\hline Sevilla & SVLL & 15 & 89.2 & 82 & 35.3 & 139 & 17.5 & 130.1 & 90 \\
\hline Fr Basque & FRBQ & 77 & 97.5 & 95 & 28.1 & 175 & 30 & 85.2 & 115 \\
\hline Br Langue & BRLA & 110 & 246.2 & 254 & 26.0 & 301 & 168 & 256.3 & 220 \\
\hline L Langue & LLAN & 104 & 223.0 & 222 & 31.1 & 326 & 108 & 227.0 & 210 \\
\hline Alles C.B. & ALES & 81 & 124.2 & 112 & 60.6 & 341 & 50 & 97.8 & 111 \\
\hline Corsica & CORS & 8 & 157.4 & 162 & 31.6 & 217 & 117.5 & 167.3 & 139 \\
\hline Sardinia & SARD & 24 & 135.7 & 136 & 29.4 & 190 & 84.5 & 151.9 & 128 \\
\hline Golan & GLAN & 45 & 261.1 & 266 & 15.2 & 279 & 213 & 271.1 & 248 \\
\hline
\end{tabular}

of statistical tools to classify the data in groups according to their statistical distance. This is the distance between two points in an $n$-dimensional parameter space. We have used the data presented in Table 3 to calculate the statistical distances between the different groups of dolmens. Finally, the data arranged according with these statistical distances are linked through a tree diagram called the dendrogram.

We have used IDL ${ }^{14}$ software to produce first the cluster analysis data and then the distances among groups (using a nearest neighbour algorithm already implemented 


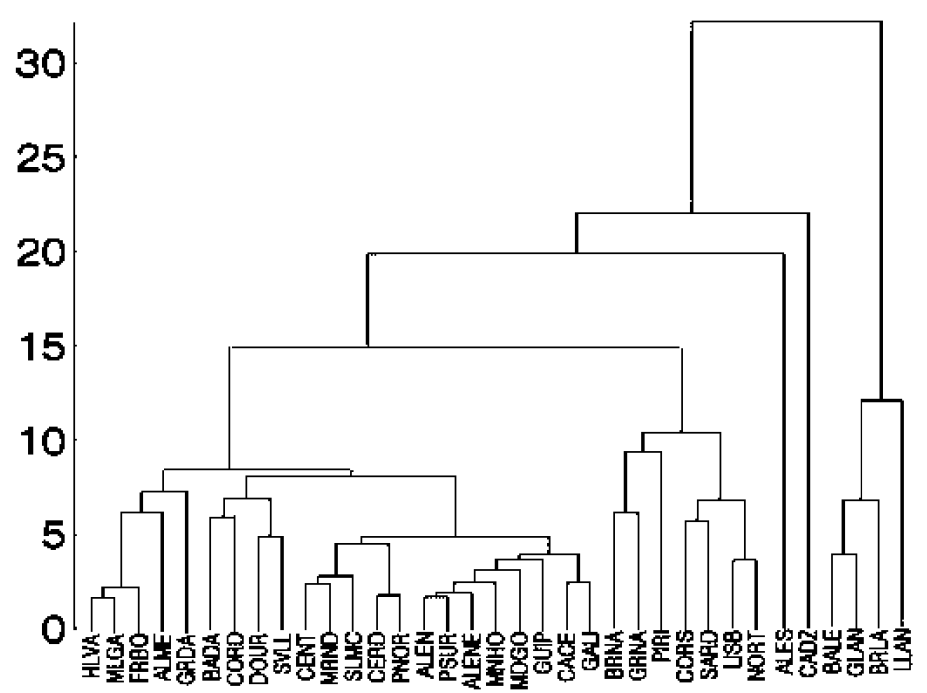

FIG. 4. Dendrogram of the clusters of megalithic tombs according to their orientation. Notice how different branches tend to cluster around groups of dolmens with similar geographic coordinates despite the fact that these magnitudes were not deliberately introduced in the analytic procedure. See the text for further discussion.

in the software) and the plotting procedures included in the package. Figure 4 shows the corresponding dendrogram for our 35 clusters. The relative distance is given on the left side of the diagram. ${ }^{15}$ This quantity will be used to find correlations between the different groups.

The first division separates the group formed by the megaliths in southern France (Languedoc and Provence) together with those in the Balearic Islands (BALE, BRLA, LLAN). It also includes the dolmens in the Golan Heights (GLAN). This situation arises because these are the only groups that include dolmens with a predominantly west-facing custom; although this could be expected, it is reassuring to find that our technique seems to work reasonably well. The dolmens of the Golan Heights, in the Levant, have been included in our analysis in order to test the consistency of our results. Since this is a case of a clear geographic outlier in our sample, it should provide information on the robustness of our analysis technique. This cluster of dolmens presents orientations towards the western part of the horizon (see Figure 2), a custom that is alien to most clusters in the Iberian Peninsula. Hence, our dendrogram analysis confirms this aspect by placing the Golan cluster next to the dolmens in the Balearic Islands and the South of France.

In the next step, the allées couvertes from Brittany (another alien group: ALES) and the few dolmens from the province of Cadiz (CADZ) are clearly separated from the rest. These two clusters present orientations mostly towards the southern 


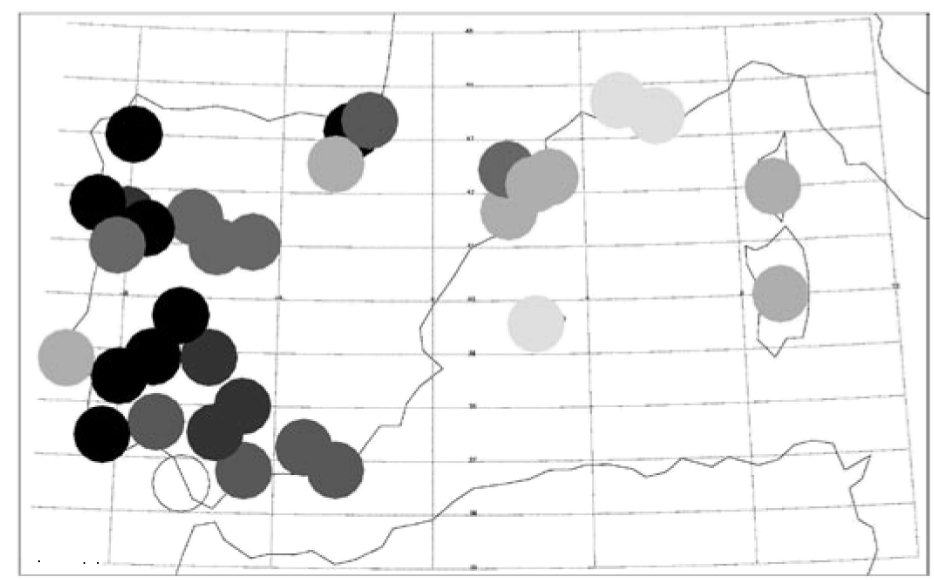

FIG. 5. Groups identified as closely related in the dendrogram analysis are plotted here with a similar grey scale. The geographic tendency of orientations is clearly signalled. Note the clustering of groups in the Atlantic façade, the Douro valley, and Andalusia.

part of the horizon. Two big groups divide at a distance of nearly 15, one including dolmens mostly located in the northeast of the Iberian Peninsula and the Mediterranean islands, and the other including the remaining clusters further to the west of the Iberian Peninsula. The first group is further divided at $\sim 10$ into those properly in the northeast (BRNA, GRNA, PIRI), and the rest (CORS, SARD, LISB, NORT). We shall not follow further divisions along this branch of the tree.

Most interesting, however, is the fact that at the other branch at a level of $\sim 8$ a new group is separated formed mainly by clusters in the south of the Iberian Peninsula (HLVA, MLGA, FRBQ, ALME, GRDA). The other western big group is soon divided into another two associations (distance $~ 7$ ), one formed by four groups close to Seville (SVLL, BADA, CORD, DOUR) and the other consisting of the remaining groups. Finally, this remaining grouping divides at a level of $\sim 4$ into two big groups, one including mainly groups in central Iberia (CENT, MRND, SLMC, CERD, PNOR), and the other containing the remaining ones, located predominantly in the Atlanticfacing part of the peninsula (ALEN, PSUR, ALENE, MNHO, MDGO, GUIP, CACE, GALI). Figure 5 shows the association of these different groups by similar shades of grey in a map of the western Mediterranean region.

It is worth noting that the groupings produced by this dendrogram analysis are mainly related by geographic coordinates. We need to stress that these geographic coordinates are not included as input data, which in fact include only orientation data. Hence, we may conclude that geographically close areas present similarities in the orientation customs of the megalithic tombs found there, regardless of type of construction and epoch; that is, orientation customs are shared by connected areas through time. One possible inference from this image is that there is a growth of diversity as we move away from the Atlantic side of Iberia. The connection between different 
clusters in the Douro Valley and Andalusia (first in the Guadalquivir Valley and later to the southeast) might indicate the progress of a pattern following well-established geographical routes. Unfortunately, the absence of measurable monuments in the Cantabrian part of the Iberian Peninsula and the total absence of monuments in Levante preclude any further conclusions on this particular aspect.

However, it is also interesting to note that, although the geographic similarities are clear, there are a number of groups that we may call interlopers. These share common orientation characteristics with groups from geographically disconnected areas within the Iberian Peninsula. A closer look at Figure 5 shows that some of these groups are, on the one hand, in areas of southern France or the Pyrenees (French Basque Country, county of Cerdagna, province of Guipúzcoa) where we did not include neighbouring areas from France in this analysis, or where they present a small number of members, where the low-number statistics may hamper a correct comparison as in Douro North or the region of Lisbon.

In any case, the interlopers may provide a further test of the astronomical intention behind the orientation patterns. If areas so geographically distant as the French Basque Country and Málaga share orientation customs, the only possible explanation ought to be astronomical. To test this hypothesis further we must advance yet another step in our work and attempt a comparison with astronomical models. We will try to perform this in the next section through a principal components analysis.

\section{Principal Components Analysis}

Principal components analysis (hereafter PCA) searches for the directions of maximum variance in a set of data. These directions are the so-called principal components. ${ }^{16} \mathrm{We}$ can then present the data in terms of the new coordinate axes defined by the principal components. Once we have computed the principal components, we give each group of monuments a new set of coordinates in the space defined by the principal components. $97.3 \%$ of the variance in our sample is actually described by the first three principal components (PCs hereafter). The first three PCs are a linear combination of the seven genetic markers, named from A to G:

$\mathrm{PC} 1=0.0035 \mathrm{~A}+0.0035 \mathrm{~B}+0.0003 \mathrm{C}+0.0042 \mathrm{D}+0.0027 \mathrm{E}+0.0035 \mathrm{~F}+0.0033 \mathrm{G}$

$\mathrm{PC} 2=-0.0015 \mathrm{~A}-0.0026 \mathrm{~B}+0.0052 \mathrm{C}+0.0147 \mathrm{D}-0.0124 \mathrm{E}-0.0040 \mathrm{~F}-0.0007 \mathrm{G}$

$\mathrm{PC} 3=-0.0044 \mathrm{~A}-0.0094 \mathrm{~B}-0.0041 \mathrm{C}+0.0020 \mathrm{D}+0.0060 \mathrm{E}-0.0125 \mathrm{~F}+0.0209 \mathrm{G}$

The first two PCs (PC1 and PC2) explain $~ 90 \%$ of all the variance and thus indicate that our data could be seen as a 'plane' in the three-dimensional space defined by PC1, PC2 and PC3 (see Figure 6). PC1 is indeed a combination of all our genetic markers, with a minimal contribution from the standard deviation of the azimuths (called $\mathrm{C}$ above). The main contributors of $\mathrm{PC} 2$ are the maximum and minimum azimuths (called D and E), i.e. the orientation range. Finally, the factors with a maximum absolute contribution to PC3 are the two maxima in the azimuthal kernel density distribution (called $\mathrm{F}$ and $\mathrm{G}$ ). 


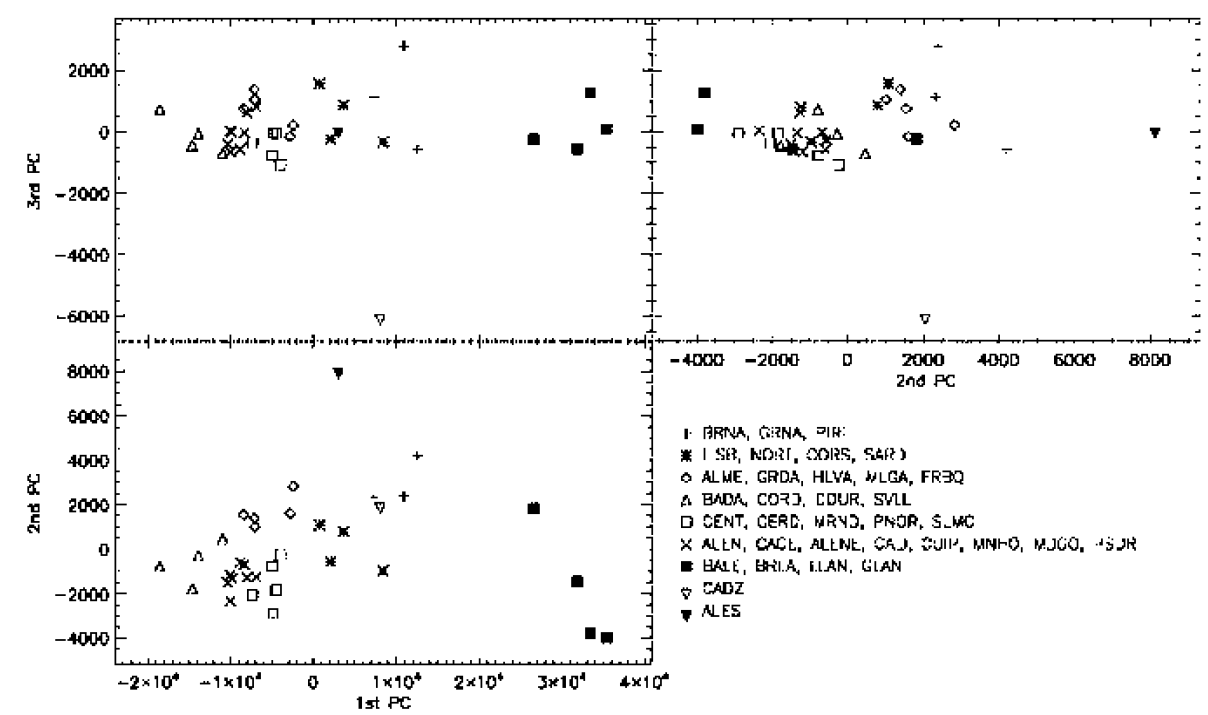

FIG. 6. Principal components analysis for the 35 clusters, identified with symbols according to larger groups as resulting from the analysis of the dendrogram. The three plots present a three-dimensional view of the space where we can find that the PCA keeps similar relations as shown in Figs 4 and 5.

We restricted ourselves to these three coordinates, and neglected the last four PCs in our analysis without much loss of information.

This procedure also highlighted the presence of groupings among clusters, as shown in Figure 6. The plot shows the PCs for the 35 groups in our analysis. We have basically found similar results to those presented before for the dendrogram study: the two techniques demonstrate that the clusters of dolmens group together in a similar way. For example, the western orientation clusters (BALE, BRLA, LLAN, GLAN) are clearly selected as an independent group when the first component is considered. Besides, the importance of the dolmens of the Atlantic façade (ALEN, CACE, ALENE, GALI, GUIP, MNHO, MDGO and PSUR, depicted as crosses in Figure 6) are clearly characterized as they are located in the centre of gravity of a large grouping of clusters, perhaps indicating the idea of an earlier origin for these monuments that is also supported by carbon and thermoluminiscent dating. ${ }^{17}$

Additionally, an interesting characteristic of the PCA method is that we can also include control data obtained from models and see how the clusters of true data group together around some of these models. This procedure would allow us to distinguish and discriminate amongst those models with a better fit to the data in a first step, before actually performing true modelling of such data, and consequently saving analysis time. However, we should note that including the control data modified the matrix for computing the PCs, so that the new coordinate system was slightly different from that without models, also modifying the relative positions in the PC plot.

We performed several models for the rising and setting of the sun and the full moon 
for different periods of the year. Parameters were obtained from the works of Green and Meeus. ${ }^{18}$ We computed the rising positions for the sun and the moon for 148 years in order to have enough data to do reliable statistics. We used our own software, developed to calculate such models, and extracted from the control distribution pattern the same data as we did for the real dolmens' orientation patterns. We have included ten models in our analysis. Models for the moon are: LUNA, all possible positions of the moon during a year; LEP, the full moon after the spring equinox; LEP1, the full moon one month after the spring equinox; LEO, the full moon after the autumn equinox; LSV, the full moon around summer solstice; SOL, all possible positions of the sun in one year; SSI, the sun around winter solstice; SSV, the sun around summer solstice; SEP, the sun around spring equinox; and SEO, the sun around autumn equinox. The comparison with the data is done by computing the azimuths for these solar and lunar events at the latitude of the centre of the Peninsula. As mentioned in the Data Mining section, the range of azimuths covered by the megalithic tombs data is quite large, and choosing a particular latitude could hamper this comparison, especially for those groups far from the latitudes of the centre of the Peninsula. To address this issue, we have performed a robustness test by calculating the variation of the models by considering that the latitudes are the ones of the Provence and Cadiz dolmens, i.e. the two extremes to the north and south of our core sample. The variations in the positions of the models in the PCA diagrams are in all cases smaller than the size of the symbol used in Figure 7 to show that model.

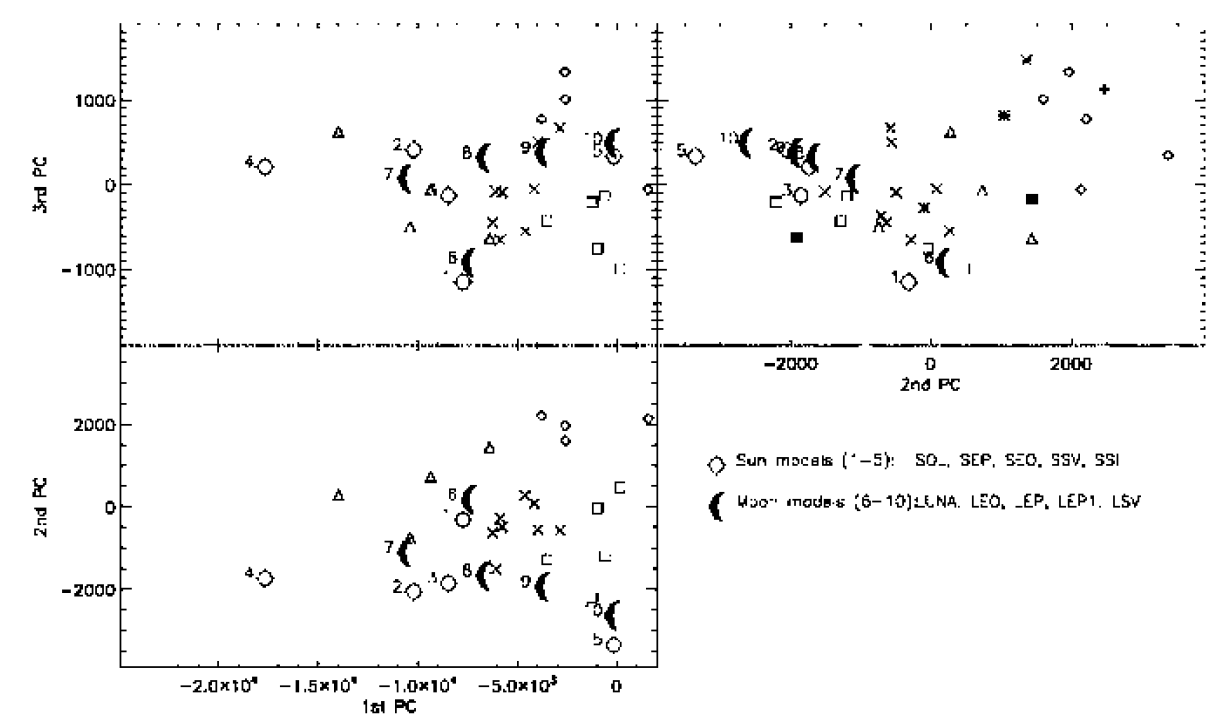

FIG. 7. Principal components analysis for the 35 clusters plus the models of the sun and the moon. The lunisolar models are identified with either a sun or moon symbol plus a number referring to each particular model. The seven-stone antas are showed with a bold cross. See the text for further discussion. 
Figure 7 shows the results. Interestingly, a significant fraction of the megaliths appear to group together around specific models. In some cases, we observed a closer link to certain solar or lunar models although, in general and in a three-dimension space, lunar models are apparently closer to the data than the solar ones. For example, it is reassuring to find that this method may also link the antas from Alentejo (and the other clusters belonging to that group depicted as crosses, see Figure 7) with the spring full moon (model 8; the closer model in a 3-dimension space as opposed to the autumn equinox sun, model 3) as proposed by Marciano da Silva. ${ }^{19}$ The group of clusters in the central area of the Peninsula (CENT, CERD, MRND, PNOR, SLMC; squares in Figures 6 and 7) seem to be closer in the 3D space to the model of the summer solstice moon (model 10) than to the winter solstice sun (model 5). The groups of the south and southeast (ALME, GRDA, HLVA, MLGA, FRBQ) appear less clearly connected with the different models attempted in the present paper.

In order to account fully for more secure relationships, a group-by-group modelling should be performed. Indeed, the PCA technique is not a modelling procedure, nonetheless it is clearly shown to be a useful tool for discriminating among several different models. Further, these models could be used in a next step as input models to directly compare with the data in a way similar to that already applied for the dolmens in southern France. ${ }^{20}$

\section{Conclusions}

The dendrogram and PCA have clearly demonstrated that there is a link between geographic coordinates of the clusters of dolmens and their respective orientation, as it was already attested by Hoskin. ${ }^{21}$ Neighbouring clusters of dolmens in the Iberian Peninsula tend to share orientation characteristics. This conclusion is true regardless of the type of dolmen and the epoch of construction. This recalls a persistence of orientation custom and a necessary communication between neighbouring regions.

In a general context, both analyses present a consistent picture where orientation patterns are defined by geographic proximity to another cluster with a given orientating pattern. In this sense, it is interesting to remember that the Alentejo dolmens (where we find some of the oldest dating) are close to the centre of mass of the PCA diagram. In this sense we could identify a connection of most groups in the western façade of the Peninsula with a possible spread towards the southeast of the Iberian Peninsula (via the groups of BADA, CORD and SVLL) and another one to the northeast across the Douro valley. However, the groups in the northeast of the Iberian Peninsula and the Islands should most probably be connected with those in southern France. As a consequence of this spread, the orientation customs and possible targets changed, as demonstrated by the PCA analysis.

To test these hypotheses further, it would be highly desirable to obtain orientation data from the area of the Cantabrian façade (Asturias and Cantabria) to see if there is a connection through the coast also towards the Pyrenees, and also across the central Pyrenees. The first case is problematic because most Cantabrian megaliths are of 
the cairn type and hence are difficult to measure, although a number of measurable dolmens have been recently reported. The situation is more promising with the monuments of the province of Huesca where a few dozen monuments, not yet measured, have been reported. These will be the objective of a future campaign. Besides, on a few occasions, the patterns of orientations can be generally explained by simple astronomical models involving the sun or the moon, although a certain lunar preference has been emphasized.

Changing the latitude where the models are applied produces only a very small variation of the models in the PCA diagrams. This indicates that the method is quite robust and the results meaningful, allowing us to discriminate among different possibilities. Finally, robustness tests performed with clear geographic outliers show that the technique is adequate and provides a useful insight into developing further modelling of the dolmen orientations on a firmer basis.

\section{Acknowledgements}

We would like to thank the referee for stimulating comments and suggestions that helped to improve the quality of this paper. This work is partially financed in the framework of the projects P310793 “Arqueoastronomía” of the Instituto de Astrofísica de Canarias, and AYA2007-60213 "Orientatio ad Sidera II" of the Spanish Ministry of Science and Innovation.

\section{REFERENCES}

1. M. Hoskin, Tombs, temples and their orientations: New perspectives in Mediterranean prehistory (Bognor Regis, 2001; hereafter Tombs, temples).

2. Hoskin, Tombs, temples (ref. 1).

3. C. Marciano da Silva, "The spring full moon", Journal for the history of astronomy, xxxv (2004), $475-8$.

4. Hoskin, Tombs, temples (ref. 1).

5. P. R. Freeman and W. Elmore, "A test for the significance of astronomical alignments", Archaeoastronomy (supplement to Journal for the history of astronomy), no. 1 (1979), S86-96; D. C. Heggie, "Highlights and problems of megalithic astronomy", Archaeoastronomy, no. 3 (1981), S15-37.

6. J. Patrick and P. Freeman, "A cluster analysis of astronomical orientations", in Records in stone: Papers in memory of Alexander Thom, ed. by C. L. N. Ruggles (Cambridge, 1988), 251-61; C. L. N. Ruggles, Megalithic astronomy: A new archaeological and statistical study of 300 western Scottish sites (British Archaeological Report 123; Oxford, 1984).

7. A. C. González-García, L. Costa-Ferrer and J. A. Belmonte, "Solarists vs. lunatics: Modelling patterns in megalithic astronomy" in Light and shadows in cultural astronomy, ed. by M. Zedda and J. A. Belmonte (Cagliari, 2007), 23-30.

8. M. V. García Quintela and A. C. González García, "Arqueoastronomía, antropología y paisaje", Complutum, xx/2 (2009), 39-54.

9. For genetics, see Y. Moodley et al., "The peopling of the Pacific from a bacterial perspective", Science, cccxxiii (2009), 527-30 and references therein. For linguistics, see R. D. Gray, A. J. Drummond and S. J. Greenhill, "Language phylogenies reveal expansion pulses and pauses in Pacific settlement", Science, cccxxiii (2009), 479-83; for a review see L. L. Cavalli-Sforza, "Genes, peoples and languages", Proceedings of the National Academy of Sciences, xciv (1997), 
7719-24.

10. Michael Hoskin, "The orientation of Neolithic monuments of Brittany: (2) The early dolmens", and "(3) The allées couvertes", Journal for the history of astronomy, xxxviii (2007), 487-501.

11. R. Gil-Merino, M. A. Moreno Gallo, G. Delibes de Castro and A. C. González-García, "Interdisciplinary approach to megalithic tombs in Northern Iberia", in Cosmology across cultures, ed. by J. A. Rubiño-Martin et al. (Astronomical Society of the Pacific Conference Series cdix; San Francisco, 2009), 349-53.

12. A. C. González-García, "Estudio estadístico de las orientaciones de los megalitos de la Península Ibérica", Complutum, xx/2 (2009), 177-86.

13. See, for example P.-K. Tan, M. Steinbach and V. Kumar, Introduction to data mining (Wilminton, 2006).

14. IDL stands for Interactive Data Language. This is software developed by ITT Visual Information Systems, Inc. This program includes a number of mathematic and visualization tools developed to work with scientific data.

15. This magnitude has no physical meaning.

16. See, for example D. C. Lay, Linear algebra and its applications (Wilminton, 1994).

17. Manuel Calado, personal communication. E. H. Whittle and J. M. Arnaud, "Thermoluminiscent dating of Neolithic and Chalcolithic pottery from sites in central Portugal", Archaeometry, xvii (1975), 5-24.

18. R. M. Green, Spherical astronomy (Cambridge, 1991); J. Meeus, Astronomical algorithms (Richmond, 1991).

19. Marciano da Silva, op. cit. (ref. 2).

20. González-García et al., op. cit. (ref. 7).

21. Hoskin, Tombs, temples (ref. 1). 